\title{
Quality of life among young adults with obsessive compulsive disorder: a population-based study
}

\begin{abstract}
Background: Obsessive Compulsive Disorder (OCD) is characterized by the presence of obsessions and compulsions and has a negative impact on quality of life (QoL) of those who suffer from this disorder.
\end{abstract}

Aim: To evaluate the relationship between OCD and (QoL) among young adults between 18 and 24 years in the South Brazil.

Methods: The OCD was evaluated using the Mini International Neuropsychiatric Interview and QoL using the Medical Outcomes Study 36 - Item Short-Form Health Survey. ANOVA and T test were used to compare means. Linear regression was applied to control confounding factors.

Results: The study sample comprised 1560 individuals. The prevalence of OCD was $3.3 \%$. Means were lower in young people with OCD in all QoL domains $(\mathrm{p}<0.05)$.

Conclusion: Studies on QoL with OCD individuals may help health professionals and patients to better understand the nature and extent of the suffering associated with this disorder.

Keywords: quality of Life, obsessive compulsive disorder, young adults
Volume I Issue 2 - 2017

\author{
Jéssica Puchalski Trettim, Andressa Jacondino \\ Pires, Mariana Bonati de Matos, Karen Jansen, \\ Ricardo Azevedo Silva, Lucianade Avila \\ Quevedo \\ Postgraduate Program in Health and Behavior, Universidade \\ Católica de Pelotas, Brazil
}

\author{
Correspondence: Jéssica Puchalski Trettim, Postgraduate \\ Program in Health and Behavior, Universidade Católica de \\ Pelotas, Brazil, Tel +55(53)984224873, \\ Email jessicatrettim@gmail.com
}

Received: July 19, 2017 | Published: September 15, 2017
Abbreviations: OCD, obsessive compulsive disorder; WHOQOL, world health organization quality of life group; ASSIST, alcohol smoking and substance involvement screening test; MINI, mini neuropsychiatric interview

\section{Introduction}

Quality of life has been defined by the WHOQOL Group (World Health Organization Quality of Life Group) as "individuals' perception of their position in life in the context of the culture and value systems where they live and in relation to their goals, expectations, standards, and concerns". It also involves the social and physical functioning, interpersonal relationships, mental wellbeing, health perception and physical pain. ${ }^{1}$ For the mental health aspect, the specific psychopathology of any disorder can distort the subjective evaluation of different aspects of quality of life. This is the case, for example, of marked sadness in depression; euphoric symptoms in mania; distortion of reality experienced in schizophrenia and cognitive impairment perceived in situations of dementia or mental delay. ${ }^{2}$ In anxiety disorders, changes in perception of quality of life can be observed, whereas symptoms such as anxiety and fear leads to exaggerated damage in various aspects of individual's life. ${ }^{3}$ Among the anxiety disorders, obsessive compulsive disorder (OCD) a mental disorder characterized by intrusive thoughts (obsessions) and repetitive behaviours or mental rituals (compulsions) - has a negative impact on quality of life of more than $20 \%$ of those with the disorder.

The severity of obsessive compulsive symptoms and the presence of comorbities predict a lower quality of life in patients with OCD. These patients present lower scores on general health and social functioning domains. However, it is noteworthy that psychiatric comorbidity may be a confounding factor, since it can influence the perception of quality of life. ${ }^{4,5}$ It is common that the disorder causes impairment in family, social and occupational areas. ${ }^{6}$ Severe patients usually have a higher level of unemployment and difficulties ofaccess to health care facilities. According to Hertenstein et al. ${ }^{7}$ the OCD has a prevalence of approximately 2 to $3 \%,{ }^{7}$ and their symptoms cause great impact on daily activities, especially when there are comorbidities involved, such as depression. ${ }^{4}$ Young people are the most affected by the severity of symptoms, since they perform many tasks and need a good quality of life to perform their duties. As the onset of obsessivecompulsive disorder usually occurs during adolescence or young adulthood, it is likely that the individual shows symptoms for a long time, and they become more serious and crystallized over the years, especially if there is no demand for treatment and psychological monitoring. ${ }^{1-8}$ Sociodemographic factors such as unemployment, being single, medical and psychiatric comorbidities are cited as indicators of poor perception of quality of life in patients with OCD. ${ }^{5}$ The use of alcohol or other drugs also affects quality of life in young people with $\mathrm{OCD}$, and these psychoactive drugs are sometimes used improperly to treat the disorder symptoms. ${ }^{6}$

Psychiatric diagnoses are difficult to modify, but what we expect nowadays is to obtain indicators of reduced symptoms and improved quality of life, as a therapeutic result. Research on treatment efficacy has focused on the effects related to symptoms, with the main outcome parameters being the reduction of obsessive/compulsive symptoms or symptoms of depression. In addition, quality of life has increasingly been recognized as an important but rather under-investigated outcome component. ${ }^{7}$ The association between OCD and quality of life allows health professionals and patients to better understand the nature and extension of the suffering associated with the disorder, and may be useful in developing new treatment strategies focused on aspects of quality of life. ${ }^{1}$ Thus, this study aimed to evaluate the relationship between OCD and quality of life in individuals, between the ages of 18 and 24 years, in a population sample of the city of Pelotas. 


\section{Methods}

\section{Design}

This was a cross-sectional, population-based study including individuals young adults aged 18 to 24 years and living in the urban area of Pelotas, state of Rio Grande do Sul, Brazil.

\section{Sample}

The sample selection was performed by clusters, considering a population of 39.667 in the age range of interest according to the current census of 448 sectors in the city. To ensure the necessary sample size, 89 census-based sectors were randomly selected. Household selection in the sectors was performed according to a systematic sampling process, the first house being the one at the corner designated by IBGE (IBGE, 2008; http://ibge.gov.br) as starting the sector; every third house was selected.

\section{Procedure}

The study included seven interviewers, all of whom were undergraduate psychology or physical therapy students of Universidade Católica de Pelotas (UCPel). The interviewers were trained to administer the instrument by psychologists with extensive experience and weekly meetings were conducted throughout the data collection period. The interviews were conducted at home and lasted for about 40 minutes. After identifying the subjects, the interviewers were previously trained about the details of the application of instruments. The data were collected between August 2007 and December 2009. Young people that were unable to answer the diagnostic interview due to physical or cognitive problems were excluded.

\section{Variables and instruments}

\section{Obsessive compulsive disorder}

A Brazilian Portuguese validated version of the Mini Neuropsychiatric Interview (MINI) by Amorim (2000), a structured interview with proven validity and reliability, was used in the study. MINI is a brief standardized diagnostic interview designed for clinical practice and research use, and aims to classify respondents in a consistent way with DSM - IV and ICD-10 criteria. MINI was applied to evaluate the major depressive disorder. ${ }^{9}$

\section{Quality of life}

The Medical Outcomes Study 36-Item Short-Forma Health Survey- SF-36 a set of generic, coherent, and easily administered quality-of-life measures, was used in the present study. It is a multidimensional questionnaire consisting of 36 items grouped into 8 domains as follows: physical functioning, physical role, bodily pain, general health, vitality, social functioning, emotional role, and mental health. Domain scores ranged from 0 to $100(0=$ "worst health status" and $100=$ "best health status". ${ }^{10}$

\section{Alcohol abuse}

The specific module, Alcohol Smoking and Substance Involvement Screening Test (ASSIST), was selected for this study. ${ }^{11}$ The classification of abuse/dependence was considered. Each answer corresponds to a score ranging from 0 to 4 , with the total score ranging from 0 to 20 . The score range 0 to 3 indicated occasional use of alcohol, 4 to 15 revealed abuse and $\geq 16$ as suggestive of addiction.

\section{Sociodemographic data health and behavior variables}

A self-report questionnaire was used to obtain sociodemographic data: gender, marital status, education, work (some occupation from income, regardless of the workload) and socioeconomic status (according to the Economic Classification for Brazil of the Brazilian Association of Population Survey Companies, that classifies individuals into classes $\mathrm{A}+\mathrm{B}$ high/middle class; $\mathrm{C}$ lower middle class; D+E low class). ${ }^{12}$ Moreover, variables were collected concerning the self-report of any physical ailment (current our past) that the participant considered important (poliomyelitis, encephalitis, meningitis, frequent throat infection, coma, convulsion, head injuries with loss of consciousness, migraine headache, asthma, diabetes, hypothyroidism, hyperthyroidism, rheumatic fever, cerebrovascular accident).

\section{Ethical aspects}

This project was approved by the Ethics Committee of the institution, protocol number 2006/96. All participants signed a free and informed consent. People who showed any indication of psychological or psychiatric disorder according to MINI criteria were referred to psychological/psychiatric care in a health service.

\section{Processing and data analysis}

Data were analyzed using SPSS 21.0 software. The t-test and analysis of variance (ANOVA) were used to compare means and linear regression for adjusted analysis. We proposed a hierarchical conceptual model for data analysis, in which the first level referred to sociodemographic variables (socioeconomic status, gender, living with a partner, work and study); the second level consisted of variables: alcohol abuse, any important disease and major depressive episode; and the third level comprised OCD. Variables with $\mathrm{p}<0.20$ were adjusted for analysis according to the levels proposed by the hierarchical model. ${ }^{13}$

\section{Results}

Of the initial 1762 subjects identified for study inclusion, $11.5 \%$ refused to participate. Thus the final sample was composed of 1569 participants. The prevalence of OCD was 3.3\% $(n=51)$. The sociodemographic, behavioural and psychological characteristics of the sample are summarized in Table 1. For the bivariate analysis, the young adults from classes D and $\mathrm{E}$ had lower means in quality of life in the following domains: Physical Functioning, Physical Role, General Health $(\mathrm{p}=0.000)$, Emotional Role $(\mathrm{p}=0.001)$, Mental Health, Social Functioning $(\mathrm{p}=0.012)$ and Bodily Pain $(\mathrm{p}=0.000)$. It was found that women had lower means in the Physical Functioning, General Health, Vitality, Emotional Role, Mental Health, Social Functioning and Bodily Pain $(\mathrm{p}=0.000)$. Youngsters who lived with a partner had lower means in Social Functioning and Bodily Pain ( $p=0.001$ ); and those who were not working, had lower means in Social Functional $(p=0.001)$, General Health $(p=0.006)$, Emotional Role, Mental Health $(\mathrm{p}=0.000)$ and Social Functioning $(\mathrm{p}=0.003)$.

Those who were not studying had lower means in Social Functioning $(\mathrm{p}=0.000)$, Physical Role $(\mathrm{p}=0.003)$ and Bodily Pain $(\mathrm{p}=0.002)$. Individuals who had alcohol abuse presented lower means in the domains: Physical Role ( $\mathrm{p}=0.018)$, General Health $(\mathrm{p}=0.000)$, Vitality $(p=0.003)$, Emotional Role $(p=0.000)$, Mental Health $(\mathrm{p}=0.002)$, Social Functioning and Bodily Pain $(\mathrm{p}=0.000)$; and those who reported having any major disease had lower means in all areas 
$(\mathrm{p}=0.000)$ (Table 2$)$. In the adjusted analysis, the following variables that remained associated with Physical Functioning were: gender $(\mathrm{p}=0.000)$; work $(\mathrm{p}=0.013)$; presence of severe disease $(\mathrm{p}=0.001)$; current major depressive episode $(\mathrm{p}=0.000)$ and $\mathrm{OCD}(\mathrm{p}=0.005)$. Women were 4.4 points $(95 \%$ CI: $2.8,6.1)$ lower on average in Physical Functioning compared to men. Young people who were not working had 2.0 points $(95 \%$ CI: $0.4,3.6)$ lower on average than those who were working. Those who reported having any major disease showed at least 3.7 points (95\% CI: $-5.9,-1.5)$ less on average than those who did not report. Those with presence of current major depressive episode had 5.6 points $(95 \%$ CI:-8.1,-3.1) lower on average and in relation to OCD, individuals had 6.4 points (95\% CI: -10.8 , -1.9) lower on average in Physical Functioning domain compared to those without OCD (Table 3). For Physical Role, the variables that remained associated with this outcome were: economic classification $(\mathrm{p}=0.000)$; history of major illness, depression and OCD $(\mathrm{p}<0.001)$.

Table I Sample distribution according to sociodemographic, behavioral and mental characteristics of young adults in the city of Pelotas-RS

\begin{tabular}{|c|c|c|}
\hline Variable & $\mathbf{N}$ & $\%$ \\
\hline \multicolumn{3}{|l|}{ ABEP } \\
\hline$A+B$ & 583 & 37.4 \\
\hline C & 751 & 48.1 \\
\hline$D+E$ & 226 & 14.5 \\
\hline \multicolumn{3}{|l|}{ Gender } \\
\hline Male & 680 & 43.6 \\
\hline Female & 880 & 56.4 \\
\hline \multicolumn{3}{|c|}{ Living with a partner } \\
\hline No & $|12|$ & 71.9 \\
\hline Yes & 439 & 28.1 \\
\hline \multicolumn{3}{|l|}{ Works } \\
\hline No & 305 & 19.7 \\
\hline Yes & 1247 & 80.3 \\
\hline \multicolumn{3}{|l|}{ Studing } \\
\hline No & 843 & 54 \\
\hline Yes & 717 & 46 \\
\hline \multicolumn{3}{|c|}{ Alcohol abuse } \\
\hline No & || $4 \mid$ & 73.1 \\
\hline Yes & 419 & 26.9 \\
\hline \multicolumn{3}{|c|}{ Any important disease } \\
\hline No & 1335 & 84.7 \\
\hline Yes & 222 & 15.6 \\
\hline \multicolumn{3}{|c|}{ Major depressive disorder } \\
\hline No & 1364 & 87.4 \\
\hline Yes & 196 & 12.6 \\
\hline \multicolumn{3}{|c|}{ Obsessive compulsive disorder } \\
\hline No & 1509 & 96.7 \\
\hline Yes & 51 & 3.3 \\
\hline Total & 1560 & 100 \\
\hline
\end{tabular}

In relation to economy status, the mean decreased 4.1 points $(95 \%$ CI:-6.1,-1.9) in each ABEP category, with the highest mean in the higher social classes. Young adults with some important disease selfreported were 9.0 points lower $(95 \%$ CI:-12.7,-5.3) in Physical Role when compared to those without any disease. Regarding to current major depressive episode, subjects had less 23.7 points $(95 \% \mathrm{C}$ :$27.8,-19.6)$ than those without the episode, and young adults with OCD had less 14 points (95\% CI: $-21.5,-6.5)$ on average compared to those without OCD (Table 3). For General Health, the variables that remained associated after adjustment for confounding factors were: gender $(\mathrm{p}=0.001)$; being employed $(\mathrm{p}=0.040)$; alcohol abuse $(\mathrm{p}=0.004)$; important disease $(\mathrm{p}<0.001)$; depression $(\mathrm{p}<0.001)$ and OCD $(p=0.003)$. Women were 1.4 scale points $(95 \%$ CI: $-3.3,0.4)$ lower than men in general health domain, young adults who were not working showed lower 2.6 scale points $(95 \%$ CI: $-0.1,5.2)$ compared to those who were working.

Individuals who suffered from alcohol abuse showed lower 3.9 scale points $(95 \%$ CI:- $6.5,-1.2)$ on average compared to those who did not and those who reported having had any major illness had 10.6 scale points (95\% CI:-13.9,-7.2) lower on average in general health. Among individuals with current major depressive episode, the average decreased 12.8 scale points $(95 \% \mathrm{CI}:-16.6 ;-91)$ and subjects with OCD were 10.3 scale points $(95 \%$ CI:-17.2,-3.5) lower than those without OCD (Table 3). For Vitality, the variables that remained associated after adjusted analysis were: gender $(p<0.001)$; alcohol abuse $(\mathrm{p}=0.013)$; OCD and depression $(\mathrm{p}<0.001)$. Women had 9.6 points $(95 \%$ CI: $7.3,11.9)$ less than men, and young people who were alcohol abuse had less 2.9 points $(95 \%$ CI: $-5.2,-0.6)$ in this area. Those with current major depressive episode had less 20.8 points (95\% CI: $-24.1,-17.4)$ and those with OCD had their average decreased by 10.8 points ( $95 \%$ CI: $-16.8 ;-4.8$ ) (Table 3 ).

For Emotional Role, the variables that remained associated were: gender $(\mathrm{p}=0.024)$; being employed $(\mathrm{p}=0.001)$; alcohol abuse $(\mathrm{p}=0.014)$; depression and OCD $(\mathrm{p}<0.001)$. Women showed 5.1 scale points $(95 \% \mathrm{CI}: 0.6,9.5)$ lower compared to men, young adults who were not working had 7.4 scale points $(95 \%$ CI: $2.9,11.9)$ lower compared to those who were working and those who presented alcohol abuse decreased by 5.6 points ( $95 \%$ CI:-10.1,-1.1) on average. Regarding the current depressive episode, the average dropped to 36.8 points (95\% CI:-43.4,-30.3) and young adults with OCD were 25.9 scale points $(95 \%$ CI:-37.7;-14.1) lower on average than those without OCD (Table 3). For Mental Health, the variables that remained associated were: economic classification $(\mathrm{p}=0.002)$; gender $(\mathrm{p}<0.001)$; working $(\mathrm{p}=0.003)$; alcohol abuse $(\mathrm{p}=0.001)$; current depressive episode and OCD $(\mathrm{p}<0.001)$.

For lower social class, the average decreased 2.8 scale points $(95 \%$ CI: $-4.6,-1.0)$ and women were 7.8 scale points (95\% CI: $5.3,10.3)$ lower on average in mental health domain as compared to men. In relation to work, individuals who were not working were 3.8 scale points $(95 \%$ CI: 1.3, 6.4) lower than those who worked and those who were alcohol abusers had 2.1 scale points less $(95 \%:-4.4,-0.1)$. The presence of individuals with current major depressive episode dropped 29.4 points (95\% CI: $-32.7,-26.0)$ and those with OCD had 16 points (95\% CI:-22.1,-9.9) less in this domain. For Social Functioning, the variables that remained associated were: gender $(\mathrm{p}<0.001)$; important disease $(\mathrm{p}=0.015)$, depression and $\mathrm{OCD}(\mathrm{p}<0.001)$. Women were 5.6 scale points $(95 \% \mathrm{CI}: 2.8,8.4)$ lower than men and individuals with a history of major disease decreased 4.4 points $(95 \%$ CI: $-8.0 ;-08)$. Regarding current major depressive episode, subjects had 26.2 scale 
points (95\% CI:-30.2,-22.1) lower on average in social functioning domain compared to those without current major depressive episode. For OCD, there was a decrease of 14.6 points (95\% CI:-21.9,-7.3) on average compared to the young adults without OCD. For Bodily Pain, the variables that remained associated were: economic classification $(p=0.014)$; gender $(p<0.001)$; alcohol abuse; important disease; depression $(\mathrm{p}<0.001)$ and $\mathrm{OCD}(\mathrm{p}=0.002)$.

Table 2 Distribution of the sample and SF-36 means for young adults in the city of Pelotas-RS

\begin{tabular}{|c|c|c|c|c|c|c|c|c|}
\hline \multirow[t]{3}{*}{ Variable } & Physical & Role physical & General health & Vitality & Role emotional & Mental health & $\begin{array}{l}\text { Social } \\
\text { functioning }\end{array}$ & Bodily pain \\
\hline & functioning & mean ( $\pm s d)$ & mean ( $\pm s d)$ & mean( $( \pm s d)$ & mean ( $\pm s d)$ & mean ( $\pm s d)$ & mean ( $\pm s d)$ & mean ( $\pm s d)$ \\
\hline & mean $( \pm s d)$ & & & & & & & \\
\hline \multicolumn{9}{|l|}{ ABEP } \\
\hline$A+B$ & $93.5(10.8)^{*}$ & $88.6(18.4)^{*}$ & $78.8(18.4)^{*}$ & $61.1(16.8)^{* * *}$ & $81.3(31.3)^{*}$ & $76.2(17.9)^{*}$ & $85.1(20.4)^{*}$ & $77.2(19.1)^{*}$ \\
\hline C & $91.9(13.0)$ & $85.4(28.1)$ & $76.4(20.0)$ & $60.4(18.8)$ & 79.8 (33.9) & $74.0(20.6)$ & 83.7 (22.7) & $74.2(21.9)$ \\
\hline$D+E$ & 89.7 (I5.5) & $78.4(32.3)$ & 73.5 (2I.7) & $59.0(20.2)$ & 71.3 (39.3) & 68.I (24.I) & $80.5(24.6)$ & 71.6 (22.7) \\
\hline \multicolumn{9}{|l|}{ Gender } \\
\hline Male & $95.2(10.1)^{*}$ & $86.4(27.1)$ & $79.7(18.8)^{*}$ & $65.8(15.0)^{*}$ & $83.4(31.1)^{*}$ & $79.3(16.8)^{*}$ & $87.2(19.8)^{*}$ & $77.8(20.4)^{*}$ \\
\hline Female & $89.8(14.0)$ & $85.0(27.8)$ & $74.8(20.2)$ & $56.3(19.5)$ & 75.8 (35.7) & $69.8(21.9)$ & $81.0(23.5)$ & $72.8(2 \mathrm{I} .4)$ \\
\hline \multicolumn{9}{|c|}{ Living with a Partner } \\
\hline No & $93.0(11.6)^{*}$ & $86.4(26.4)^{* *}$ & $76.9(19.8)$ & $60.6(17.5)$ & $79.0(33.8)$ & 74.I (20.I) & $83.4(22.2)$ & $76.1(20.5)^{*}$ \\
\hline Yes & $90.3(15.1)$ & $83.7(30.1)$ & $76.9(19.5)$ & $60.0(20.2)$ & 79.5 (34.3) & $73.6(21.0)$ & $84.5(22.3)$ & $72.0(22.3)$ \\
\hline \multicolumn{9}{|l|}{ Working } \\
\hline No & $90.9(13.9)^{*}$ & $85.0(28.1)$ & $74.9(20.9)^{*}$ & $58.9(18.8)^{* *}$ & $74.3(38.0)^{*}$ & $7 I .0(2 I .5)^{*}$ & $81.4(23.8)^{*}$ & $73.8(21.8)$ \\
\hline Yes & $93.8($ (II.2) & 86.I (27.7) & $78.3(18.3)$ & $61.0(17.9)$ & $82.8(31.5)$ & $76.8(18.5)$ & $85.8(20.3)$ & $75.4(20.5)$ \\
\hline \multicolumn{9}{|l|}{ Studing } \\
\hline No & $91.0(13.9)^{*}$ & $83.7(29.6)^{*}$ & $76.0(20.2)^{* *}$ & $60.5(19.3)$ & $78.0(34.8)^{* *}$ & $73.4(21.2)$ & $82.8(23.0)^{* *}$ & $73.4(22.1)^{*}$ \\
\hline Yes & $93.6(11.0)$ & $87.9(24.7)$ & $78.0(19.1)$ & $60.3(17.1)$ & $80.5(32.9)$ & $74.5(19.3)$ & $84.8(2 I .1)$ & $76.8(19.8)$ \\
\hline \multicolumn{9}{|c|}{ Alcohol Abuse } \\
\hline No & $92.4(12.8)$ & $88.6(26.6)^{*}$ & $78.3(19.5)^{*}$ & $61.3(18.3)^{*}$ & $81.4(32.2)^{*}$ & $74.9(20.0)^{*}$ & $85.0(21.4)^{*}$ & $76.2(20.8)^{*}$ \\
\hline Yes & 91.6 (12.4) & $82.9(29.8)$ & 73.2 (19.8) & $58.2(18.2)$ & $72.9(37.6)$ & $7 I .3(2 I . I)$ & $80.3(23.9)$ & $71.7(21.5)$ \\
\hline \multicolumn{9}{|c|}{ Any Important Desease } \\
\hline No & $93.0(11.6)^{*}$ & $87.4(25.7)^{*}$ & $78.9(18.2)^{*}$ & $61.2(17.8)^{*}$ & $80.6(32.8)^{*}$ & $75.0(19.7)^{*}$ & $84.9(21.0)^{*}$ & $76.3(20.2)^{*}$ \\
\hline Yes & 87.1 (I7.I) & $75.0(34.9)$ & $65.1(23.9)$ & $55.9(20.5)$ & 70.1 (39.2) & $67.7(22.9)$ & $76.5(27.2)$ & $66.8(24.7)$ \\
\hline \multicolumn{9}{|c|}{ Major Depressive Disorder } \\
\hline No & $93.4(11.5)^{*}$ & $89.1(23.4)^{*}$ & $79.4(17.6)^{*}$ & $63.4(16.0)^{*}$ & $85.1(28.2)^{*}$ & $78.5(15.9)^{*}$ & $87.6(18.3)^{*}$ & $77.4(19.4)^{*}$ \\
\hline Yes & $84.1(17.2)$ & $61.1(38.9)$ & $59.4(24.4)$ & $39.8(20.0)$ & $37.7(4 I .1)$ & $42.5(20.5)$ & $56.8(27.7)$ & $57.6(24.2)$ \\
\hline \multicolumn{9}{|c|}{ Obsessive Compulsive Disorder } \\
\hline No & $92.6(12.3)^{*}$ & $86.6(26.4)^{*}$ & $77.7(19.1)^{*}$ & $61.1(18.0)^{*}$ & $80.8(32.6)^{*}$ & $75.1(19.3)^{*}$ & $84.8(21.2)^{*}$ & $75.6(20.8)^{*}$ \\
\hline Yes & $81.2(18.9)$ & $56.3(4 I .1)$ & $54.0(25.1)$ & $40.2(16.7)$ & $31.3(39.6)$ & $40.2(22.9)$ & $52.6(27.7)$ & $54.6(21.6)$ \\
\hline Total & $92.2(12.7)$ & $85.6(27.5)$ & $76.9(19.7)$ & $60.5(18.3)$ & 79.1 (33.9) & $73.9(20.4)$ & $83.7(22.2)$ & $75.0(21.1)$ \\
\hline
\end{tabular}

$* \mathrm{P} \leq 0.05$ ( $\mathrm{T}$ test/ ANOVA)

$*_{p} \leq 0.20(T$ test/ ANOVA) 
Table 3 Linear regression adjusted analysis of quality of life domains in young adults in the city of Pelotas-RS

\begin{tabular}{|c|c|c|c|c|c|c|c|}
\hline Variable & $\begin{array}{l}\text { Physical } \\
\text { functioning }\end{array}$ & $\begin{array}{l}\text { Role } \\
\text { physical }\end{array}$ & $\begin{array}{l}\text { General } \\
\text { health }\end{array}$ & $\begin{array}{l}\text { Role } \\
\text { emotional }\end{array}$ & Mental health & Social functioning & Bodily pain \\
\hline & $\begin{array}{l}\text { B } \\
\text { (Cl 95\%) }\end{array}$ & $\begin{array}{l}\text { B } \\
\text { (Cl 95\%) }\end{array}$ & $\begin{array}{l}\text { B } \\
\text { (Cl 95\%) }\end{array}$ & $\begin{array}{l}\text { B } \\
\text { (Cl 95\%) }\end{array}$ & $\begin{array}{l}\text { B } \\
\text { (Cl 95\%) }\end{array}$ & $\begin{array}{l}\text { B } \\
\text { (Cl 95\%) }\end{array}$ & $\begin{array}{l}\text { B } \\
\text { (Cl 95\%) }\end{array}$ \\
\hline \multirow[t]{2}{*}{$\begin{array}{l}\text { ABEP } \\
(D+E)\end{array}$} & -1.1 & $\begin{array}{l}-4.1(-6.1 ; \\
-1.9)^{*}\end{array}$ & -1.4 & -2.2 & -2.8 & -1.6 & -1.7 \\
\hline & $(-2.3 ; 0.9)$ & & $(-3.3 ; 0.4)$ & $(-5.5 ; I . I)$ & $(-4.6 ;-1.0)^{*}$ & $(-3.7 ; 0.4)$ & $(-3.4 ;-0.1)^{*}$ \\
\hline $\begin{array}{l}\text { Gender } \\
\text { (Male) }\end{array}$ & $4.4(2.8 ; 6.1)^{*}$ & & $4.1(1.6 ; 6.6)^{*}$ & $5.1(0.6 ; 9.5)^{*}$ & $7.8(5.3 ; 10.3)^{*}$ & $5.6(2.8 ; 8.4)^{*}$ & $4.6(2.5 ; 6.8)^{*}$ \\
\hline Living with & -0.2 & $-0.2(-3.5 ; 3.0)$ & & & & $-2.0(-4.5 ; 0.4)$ & \\
\hline a partner & $(-2.1 ; 1.5)$ & & & & & & \\
\hline Working & 2 & & $2.6(-0.1 ; 5.2)^{*}$ & $7.4(2.9 ; 11.9)^{*}$ & $3.8(1.3 ; 6.4)^{*}$ & $3.1(0.2 ; 6.0)$ & \\
\hline (yes) & $(0.4 ; 3.6)^{*}$ & & & & & & \\
\hline Studing & 1.5 & I.7 (-I.I; 4.5) & $2.4(-0.1 ; 5.0)$ & $3.7(-0.8 ; 8.3)$ & & $2.1(-0.7 ; 5.1)$ & I.2(-0.9; 3.4) \\
\hline (yes) & $(-0.1 ; 3.2)$ & & & & & & \\
\hline \multicolumn{2}{|l|}{ Alcohol Abuse } & $\begin{array}{l}-2.1(-5.1 ; \\
-0.7)\end{array}$ & $-3.9(-6.5 ;-1.2)^{*}$ & $\begin{array}{l}-5.6(-10.1 ; \\
-I . I)^{*}\end{array}$ & $-2.1(-4.4 ;-0.1)^{*}$ & $-1.9(-4.7 ;-0.8)$ & $-4.2(-6.5 ;-1.9)^{*}$ \\
\hline \multirow[t]{2}{*}{$\begin{array}{l}\text { Any } \\
\text { Important } \\
\text { Desease }\end{array}$} & -3.7 & $\begin{array}{l}-9.0(-12.7 \\
-5.3)^{*}\end{array}$ & $\begin{array}{l}-10.6(-13.9 \\
-7.2)^{*}\end{array}$ & $-2.3(-8.1 ; 3.4)$ & $-1.5(-4.5 ; 1.4)$ & $-4.4(-8.0 ;-0.8)^{*}$ & $-6.9(-9.7 ;-4.1)^{*}$ \\
\hline & $(-5.9 ;-1.5)^{*}$ & & & & & & \\
\hline \multirow[t]{2}{*}{$\begin{array}{l}\text { Current } \\
\text { Major } \\
\text { Depressive } \\
\text { Episode }\end{array}$} & -5.6 & $\begin{array}{l}-23.7(-27.8 \\
-19.6)^{*}\end{array}$ & $\begin{array}{l}-12.8(-16.6 \\
-9.1)^{*}\end{array}$ & $\begin{array}{l}-36.8(-43.4 \\
-30.3)^{*}\end{array}$ & $-29.4(-32.7 ;-26.0)^{*}$ & $-26.2(-30.2 ;-22.1)^{*}$ & $-15.9(-19.1 ;-12.7) *$ \\
\hline & $(-8 . I ;-3 . I)^{*}$ & & & & & & \\
\hline \multirow[t]{2}{*}{$\begin{array}{l}\text { Obsessive } \\
\text { Compulsive } \\
\text { Disorder }\end{array}$} & -6.4 & $\begin{array}{l}-\mid 4.0(-2 \mid .5 \\
-6.5)^{*}\end{array}$ & $\begin{array}{l}-10.3(-17.2 \\
-3.5)^{*}\end{array}$ & $\begin{array}{l}-25.9(-37.7 \\
-\mid 4.1)^{*}\end{array}$ & $-16.0(-22.1 ;-9.9)^{*}$ & $-14.6(-2 \mid .9 ;-7.3)^{*}$ & $-9.1(-14.8 ;-3.2)^{*}$ \\
\hline & $(-10.8 ; 1.9)^{*}$ & & & & & & \\
\hline
\end{tabular}

With regard to economic class, the average decreased by 1.7 points (95\% CI: $-3.4,-0.1)$ in each ABEP category, with the highest average observed in upper classes. Women had less 4.6 scale points (95\% CI: $2.5,6.8)$ compared to men. Young adults who suffered from alcohol abuse showed 4.2 points ( $95 \%$ CI: $-8.1 ;-3.1)$ less and those who had some important disease decreased by 6.9 points $(95 \%$ CI: $-9.7 ;-4.1)$ compared to healthy individuals. Individuals who had current major depressive episode were 15.9 points (95\% CI: -19.1, -12.7) less, and individuals with OCD showed 9.1 points $(95 \%$ CI: $-14.8,-3.2)$ lower in bodily pain domain, compared to those without OCD (Table 3 ).

\section{Discussion}

We found that perception of quality of life was lower in youth with OCD when compared to young adults without OCD. Considering that OCD affects young people, which have a high potential level of activity in all spheres of life, it is possible to understand this association, since the negative aspects of this disorder can affect an individual's ability to succeed in daily routine, work and social environments as well as in family relationships. ${ }^{5}$ This study showed that women had lower quality of life means compared to men in some domains. It is noteworthy that women seek care in health services more, and commonly has a self-rated health worse than men, and express their symptoms more easily. ${ }^{14}$ It was also found that young people from lower social classes demonstrated poorer quality of life in Role Physical, Mental Health, Social Functioning and Bodily Pain. In this case, one should consider that in Brazil, housing conditions and poor living environment of lower class individuals may negatively impact on their quality of life. ${ }^{15,16}$

Young people who were not working showed lower means for quality of life in four of the eight domains assessed in comparison to those who were working. Thus, it is possible to understand that the age range included in the present study contributes to this association, since youth is characterized by a greater force and potential for soliciting, plus a high level of activity in all spheres of life, including 
occupational/work area ${ }^{5}$. In addition, individuals who reported having some important disease had lower quality of life scores in all assessed domains, except Role Emotional, corroborating some studies with similar results..$^{5-17}$ The presence of physical illness can lead to a greater loss of quality of life, since people suffering from different chronic diseases have to learn to live with limitations in their daily lives since the disease requires adaptation in multiple life domains, which may contribute to decreased quality of life. ${ }^{16}$ An association between alcohol abuse and worse quality of life was observed in General Health, Emotional Role, Vitality, Mental Health and Bodily Pain. A study conducted with teenagers showed that at-risk consumers and alcohol dependents showed higher chances of having a negative perception of psychological quality of life domain. ${ }^{18}$ The presence of depressive episode is also associated with a worse quality of life, and these individuals often experience a great decline in subjective and social sensations, among others. ${ }^{5-19}$ Data from the present study corroboratethis association.

\section{Conclusion}

An important limitation to be considered in this study is the lack of a severity measure of OCD symptoms. It is also worth mentioning that subjects were evaluated during a specific period. Thus, the relationship between changes in OCD symptoms and changes in specific domains of quality of life could be better evaluated over time. It is important to mention that the cross-sectional design did not allow us to assert causality, only the existence of an association between OCD and quality of life. Concluding, studies on quality of life with OCD patients may help professionals and patients to better understand the nature and extent of the suffering associated with the disorder, and may be useful in developing new treatment strategies. Information about quality of life domains particularly impaired in people with OCD may allow therapists to focus specifically on these aspects. Thus, future studies with the purpose of developing quality of life instruments to be used with OCD patients are necessary.

\section{Acknowledgements}

None.

\section{Conflict of interest}

The authors declare that they have no conflict of interest.

\section{References}

1. Niederauer KG, Braga DT, Souza FP, et al. Qualidade de vida em indivíduos com transtorno obsessivo-compulsivo: revisão da literatura Rev Bras Psiquiatr. 2007;29(3):271-278.

2. Torresan RC, Smaira SI, Cerqueira ATAR, et al. Qualidade de vida no transtorno obsessivo-compulsivo: uma revisão. Rev Psiq Clín. 2008;35(1):13-19.

3. Hou SY, Yen CF, Huang MF, et al. Quality of life and its correlates in patients with obsessive-compulsive disorder. Kaohsiung J Med Sci. 2010;26(8):397-407.
4. Castillo ARGL, Recondo R, Asbahr FR, et al. Transtornos de ansiedade. Rev Bras Psiquiatria. 2000;22(2):20-23.

5. Eisen JL, Mancebo MA, Pinto A, et al. Impact of obsessive-compulsive disorder on quality of life. Compr Psychiatry. 2006;47(4):270-275.

6. Salgado BR, Segal HD, Romero MA, et al. Perceived quality of life in obsessive-compulsive disorder: related factors. BMC Psychiatry. 2006;6:20 p.

7. Hertenstein E, Thiel N, Herbst N, et al. Quality of life changes following inpatient and outpatient treatment in obsessive-compulsive disorder: a study with 12 months follow-up. Annals of General Psychiatry. 2013;12:4 p.

8. Neto EBS. Sobrecarga de familiares de pacientes com transtorno obsessivo-compulsivo. Dissertação de Mestrado, Universidade Federal do Piauí. Teresina, Brazil; 2010. p. 1-164.

9. Amorim P. Mini Internacional Neuropsychiatric Interview (MINI): Validação de entrevista breve para diagnóstico de transtornos mentais. Revista Brasileira de Psiquiatria. 2000;22(3):106-115.

10. Ciconelli RM, Ferraz MB, Santos W, et al. Tradução para língua portuguesa e validação do questionário genérico de avaliação de qualidade de vida SF-36 (Brasil SF-36). Rev Bras Reumatol. 1999;39(3):143-150.

11. Henrique IFS, Micheli D, Lacerda RB, et al. Validação da versão brasileira do teste de triagem do envolvimento com álcool, cigarro $\mathrm{E}$ outras substâncias (ASSIST). Rev Assoc Med Bras. 2004;50(2):199-206.

12. Associação Brasileira De Empresas De Pesquisa [ABEP]. Dados com base no Levantamento Sócio Econômico (IBOPE), acessado em maio de, Brazil; 2003.

13. Victora CG, Huttly SR, Fuchs SC, et al. The role of conceptual frameworks in epidemiological analysis: a hierarchical approach. Int $J$ Epidemiol. 1997;26(1):224-227.

14. Verbrugge LM. The twain meet:empirical explanations of sex differences in health and mortality. J Health Soc Behav. 1989;30(3):282-304.

15. Buss PM. Promoção da saúde e qualidade de vida. Health promotion and quality of life. Ciência \& Saúde Coletiva. 2000;5(1):163-177.

16. Azevedo ALS, Silva RA, Tomasi E, et al. Doenças crônicas e qualidade de vida na atenção primária à saúde. Caderno de Saúde Pública. 2013;29(9):1774-1782.

17. Srivastava S, Bhatia MS, Thawani R, et al. Quality of life in patients with obsessive compulsive disorder: A longitudinal study from India. Asian Journal of Psychiatry. 2011;4(3):178-182.

18. Gordia AP, Silva RCR, Quadros TMB, et al. Variáveis comportamentais e sociodemográficas estão associadas ao domínio psicológico da qualidade de vida de adolescentes. Rev paul pediatr. 2010;28(1):29-35.

19. Cassin SE, Richter MA, Zhang KA, et al. Quality of life in treatmentseeking patients with obsessive-compulsive disorder with and without major depressive disorder. Can J Psychiatry. 2009;54(7):460-467. 